\title{
Fish oil rich diet in comparison to saturated fat rich diet offered protection against lipopolysaccharide-induced inflammation and insulin resistance in mice
}

\author{
Matam Vijay-Kumar ${ }^{1}$, Sally M Vanegas², Nilam Patel ${ }^{2}$, Jesse D Aitken ${ }^{1}$, Thomas R Ziegler ${ }^{3}$, Vijay Ganji ${ }^{2 *}$
}

\begin{abstract}
Background and Objective: Systemic chronic inflammation is linked to metabolic syndrome, type-2 diabetes, and heart disease. Lipopolysaccharide (LPS), a Gram negative microbial product, triggers inflammation through toll-likereceptor-4 (TLR-4) signaling. It has been reported that dietary fatty acids also modulate inflammation through TLR4. We investigated whether fish oil (FO) rich diet in comparison to saturated fat (SF) rich diet would confer protection from pathologies induced by LPS.

Methods: Twenty C57BL/6 mice were divided into two groups. One group received FO-diet and other received SF-diet ad libitum for 60 days. Diets were isocaloric containing 45\% energy from fat. After 60-days of feeding, blood was collected after overnight fast. Mice were allowed to recover for 4-days, fasted for 5-hours, challenged with 100 $\mathrm{ng} / \mathrm{mL}$ of LPS intraperitonially, and bled after 2-hours. After 7-days of recuperation, mice were challenged with 500 $\mathrm{ng} / \mathrm{mL}$ of LPS intraperitonially and observed for physical health.

Results: Food intake was similar in FO- and SF-fed mice. FO-fed mice compared to SF-fed mice had significantly less body weight gain $(P=0.005)$, epididymal fat weight $(P=0.005)$, fasting blood glucose $(70.8 \mathrm{vs} 83.3 \mathrm{ng} / \mathrm{dL} ; \mathrm{P}<$ $0.05), \mathrm{HOMA}-\mathrm{IR}$ (5.0 vs 13.6; $\mathrm{P}<0.019$ ), and serum cholesterol (167 vs $94 \mathrm{mg} / \mathrm{dL} ; \mathrm{P}<0.05)$. When challenged with LPS, FO-fed mice had significantly lower serum IL-1 13 compared to SF-fed mice (2.0 vs $30.0 \mathrm{pg} / \mathrm{mL} ; \mathrm{P}<0.001)$. After LPS-challenge, SF-fed mice had higher mortality, lost more body weight, and had greater decrease in blood glucose compared to FO-fed mice.
\end{abstract}

Conclusion: Overall, FO-diet compared to SF-diet offered protection against deleterious effects of LPS in mice.

\section{Introduction}

Although inflammation is part of the body's normal response to infection and injury, extreme or inappropriate inflammation is linked to the pathobiology of several diseases [1]. Systemic low-grade chronic inflammation plays a major role in the pathogenesis of insulin resistance, metabolic syndrome, obesity, type 2 diabetes mellitus (DM2), and cardiovascular disease (CVD) [2-5]. Consequently, persons with obesity, DM2, and CVD

\footnotetext{
* Correspondence: vganji@gsu.edu

${ }^{2}$ Division of Nutrition, School of Health Professions, College of Health and Human Sciences, Georgia State University, Atlanta, GA 30302, USA Full list of author information is available at the end of the article
}

experience increased markers of inflammation compared to their counterparts [6].

Toll-like-receptors (TLR) play an important role in the regulation of innate immunity [7-9] by detecting most pathogens such as bacteria, fungi, and viruses [10]. Tolllike-receptor-4 (TLR-4) is a subclass of the TLR family involved in activation of the innate immune and inflammatory response in mammals [9-11] via ligation of lipopolysaccharide (LPS), a Gram-negative bacterial endotoxin found on the outer cell membrane of bacteria. Activation of TLR-4 leads to the induction of genes for many inflammatory cytokines [9,12-14]. These cytokines are involved in inducing insulin resistance, glucose intolerance, and infiltration of macrophages into

\section{C) Biomed Central}


the adipose tissue which further leads to increased production of inflammatory markers [15-17]

Increased intake of saturated fat (SF) is linked to dyslipidemia and adiposity, which are further related to increased risk for DM2 and CVD [18]; while n-3 fatty acids present in fish oil (FO) are linked to decreased risk for these diseases [19]. However, the exact molecular mechanism linking dietary fatty acids with obesity, DM2, and CVD is not well understood. Recently, in vitro experiments have shown that TLR-4 responds to nonbacterial ligands such as lauric acid (a saturated fatty acid) and n-3 fatty acids such as eicosapentaenoic acid (EPA) and docosahexaenoic acid (DHA) [20-22]. Further, it has been shown that TLR-4 deficiency protects mice from inflammation, insulin resistance, and increased adiposity in mice fed a diet high in SF [23]. It is likely that TLR-4 is a possible link between dietary fatty acids and inflammation, insulin resistance, and DM2. In vivo studies are limited linking dietary fatty acids with TLR-4 signaling and inflammation, insulin resistance, and adiposity. Also, it is not known if FO rich diet offers protection against the TLR-4 agonist, LPS in vivo. Greater understanding of the role of TLR-4 in relation to dietary fat is important in understanding the pathobiology of insulin resistance and DM2. Therefore, the objective of this study was to investigate whether a diet rich in FO of marine origin in relation to a diet rich in SF would offer protection against endotoxemia (LPS)-induced pathologies in C57BL/6 mice.

\section{Methods}

\section{Animals and facilities}

Approval for the use of mice was obtained from the Institutional Animal Care and Use Committees of Emory University and Georgia State University, Atlanta, GA. Twenty, 4-week old male C57BL/6 mice were purchased from Jackson Laboratories (Bar Harbor, Maine, $\mathrm{ME})$. All mice were housed in metal barred cages with bedding ( 5 mice/cage). Sufficient amounts of bedding were used to keep animals clean and dry between cage changes and to prevent odors. Animals had 12 hour light and dark cycles. Bedding changes, along with cleaning and sanitation of cages and associated equipment, such as watering devices, were performed as often as necessary.

\section{Diets and treatments}

After arrival, mice went through a 4-day acclimatization period. During this period, mice were fed a regular chow diet. Twenty mice were randomly divided into two groups of 10 mice each. Diets rich in FO (product \# D08092503) and SF (product \# D05122102P) were purchased from Research Diets, Inc. (New Brunswick, NJ). Type of fat in FO and SF diets were menhaden oil and lard, respectively. The diets were isocaloric and contained $45 \%$ energy from total fat (Table 1). Enough food was provided for mice to eat ad libitum for 2 days. After this time, any unconsumed food was thrown away after weighing and the amount of food eaten were quantified.

\section{Study design}

Mice received FO and SF diets for 60 days. At the end of 60-days, all mice were fasted overnight and blood was collected using the retro-orbital method while mice were under isoflurane anesthesia. Following a 4-day recovery, both groups were fasted for 5-hours, challenged with $100 \mathrm{ng}$ of LPS intraperitonially, and bled 2hours post LPS-challenge. Then mice were allowed to recover for 7 days from the 100 ng LPS challenge. Following the recovery, mice were fasted for 5-hours, challenged with $500 \mathrm{ng}$ of LPS intraperitoneally, After 2 hours, mice were then euthanized using carbon dioxide and epididymal fat, liver, colon, and cecum were harvested. Following $100 \mathrm{ng}$ and $500 \mathrm{ng}$ LPS challenges, mice were observed for any physical abnormalities including for mortality. During recovery phases, mice were fed their respective diets. Body weights were recorded on a weekly basis, at the end of 60-day period, and at the end of LPS challenge.

\section{Reagents and biochemical analysis}

Hemolysis-free serum was generated by centrifugation of blood using serum separator tubes (Becton Dickinson, Franklin Lakes, NJ). Serum was stored at $-80^{\circ} \mathrm{C}$ until

\section{Table 1 Composition of experimental diets}

\begin{tabular}{|c|c|c|c|c|}
\hline \multirow[t]{2}{*}{ Ingredient } & \multicolumn{2}{|c|}{ Fish oil-based diet ${ }^{1}$} & \multicolumn{2}{|c|}{ Saturated fat-based diet ${ }^{2}$} \\
\hline & $g(\%)$ & Kcal & $g(\%)$ & Kcal (\%) \\
\hline Protein & 23.7 & 20 & 23.7 & 20 \\
\hline Carbohydrate & 41.4 & 35 & 41.4 & 35 \\
\hline Fat $^{1}$ & 23.6 & 45 & 23.6 & 45 \\
\hline Casein & $200(23.3)$ & 800 & $200(23.3)$ & 800 \\
\hline L-Cystine & $3(0.35)$ & 12 & $3(0.35)$ & 12 \\
\hline Corn starch & $72.8(9.88)$ & 291 & $72.8(9.88)$ & 291 \\
\hline Maltodextrin & $100(11.65)$ & 400 & $100(11.65)$ & 400 \\
\hline Sucrose & $172.8(20.14)$ & 691 & $172.8(20.14)$ & 691 \\
\hline Cellulose & $50(5.83)$ & 0 & $50(5.83)$ & 0 \\
\hline Soybean Oil & $25(2.91)$ & 225 & $25(2.91)$ & 225 \\
\hline Lard & 0 & 0 & 177.5 (20.68) & 1598 \\
\hline Menhaden oil & 177.5 (20.68) & 1598 & 0 & 0 \\
\hline Mineral mix & $10(1.17)$ & 0 & $10(1.17)$ & 0 \\
\hline Vitamin mix & $10(1.17)$ & 40 & $10(1.17)$ & 40 \\
\hline Choline bitartrate & $2(0.23)$ & 0 & $2(0.23)$ & 0 \\
\hline Cholesterol & $0.17(0.02)$ & 0 & $0.71(0.08)$ & 0 \\
\hline Total & 858.2 & 4057 & 858.2 & 4057 \\
\hline
\end{tabular}

${ }^{1}$ Source fish oil was menhaden oil.

${ }^{2}$ Source saturated fat was lard. 
analysis. Blood samples were analyzed using the HESKA CBC-Diff Veterinary Hematology System (Heska, Loveland, CO). Concentrations of IL-1 $\beta$, IL-6, TNF- $\alpha$, keratinocyte chemoattractant (KC), fasting blood glucose, serum insulin, and serum leptin were measured at the end of 60-days and after $100 \mathrm{ng}$ of LPS challenge. IL-1 $\beta$, IL-6, TNF- $\alpha$, and KC were all analyzed using ELISA kits following manufacturer instructions. ELISA kits for serum IL-1 $\beta$ (catalog \# DY401), IL-6 (catalog \# DY406), TNF- $\alpha$ (catalog \# DY410), and KC (catalog \# DY453) were purchased from R\&D Systems, Minneapolis, MN. Fasting blood glucose was analyzed with Accu-Check Advantage blood glucose meter (Roche, Florence, SC) by using blood from the tail vein. Serum insulin and leptin concentrations were analyzed using ELISA kits purchased from Linco Research Inc (St. Charles, MO). Escherichia coli LPS 0111:B6 was purchased from Sigma-Aldrich (St. Louis, MO). Homeostatic Model Assessment-Insulin Resistance (HOMA-IR) was calculated from insulin and glucose concentrations (fasting insulin $(\mu \mathrm{U} / \mathrm{mL}) \times$ fasting glucose $(\mathrm{mg} / \mathrm{dL}) / 405)$.

\section{Data analysis}

The statistical analysis was performed using GraphPad Prism Software (Version 5.0, La Jolla, CA). Normality tests were done, after which parametric (unpaired t-test) or nonparametric (Mann-Whitney U) tests were used to analyze the differences between diets. The difference between pre- and post-LPS-treatment values within the diet group was analyzed with paired t-test for normal data or with Wilcoxin Sign test for nonnormal data. Mortality rate between SF and FO diets after the $100 \mathrm{ng}$ and 500 ng LPS-challenge was analyzed with Fisher's exact test. Statistical significance was set at $P \leq 0.05$.

\section{Results}

\section{Effects of FO and SF diets, after LPS-challenge on food} intake and body and tissue weights

Total food intake during the 60-day period was not significantly different between mice that received $F O$ and SF diet $(P=0.60)$. Average body weight changes for FO and SF diet groups are presented in Figure 1. Although there was no significant difference in body weights between SF and FO diet groups at the end 60 day period (28.2 vs. 26.8 g; $P<0.186$ ), the net weight gain was significantly higher with SF diet compared to FO diet (15.6 g vs. 13.3 g; $P=0.005$ ) (Table 2). Epididymal fat was significantly increased in mice that received SF diet compared to mice that received FO diet ( 0.61 g vs. 0.45 g) $(P=0.005)$. Of organ weights at necropsy, colon weight were significantly lower in SF diet group compared to FO diet group $(P<0.013)$ Cecum and liver weights were not significantly different between two diet groups (Table 2).

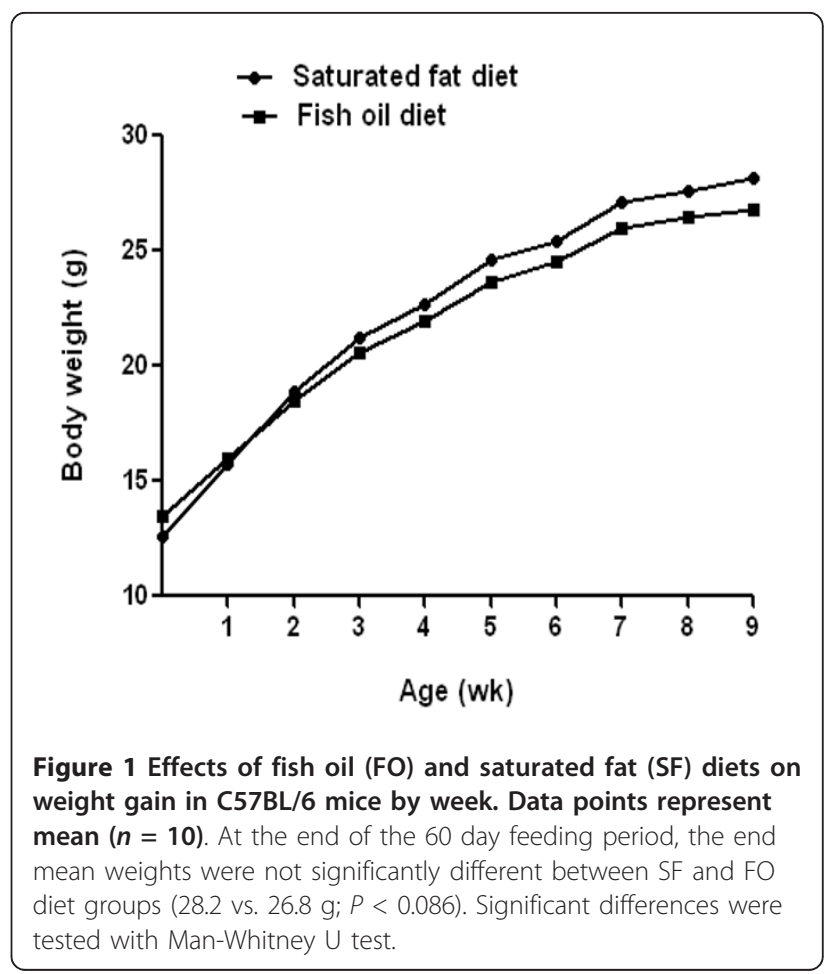

Effect of FO and SF diets, after LPS-challenge on overall well-being and mortality of mice

Mice that received SF diet in comparison to FO diet were moribund. After LPS-challenge, mice that received SF diet exhibited less or no nesting behavior. After $100 \mathrm{ng}$ LPS challenge, 1 mouse died in SF diet group but none in the FO diet group. After 500 ng LPS challenge, 1 mouse died in FO diet group and 3 mice died in SF diet group. However, the mortality rate between SF and FO diets after 500 ng LPS-challenge was not significant in Fisher's exact test. After LPS challenge, mice in SF diet group compared to FO diet group had significantly more weight loss (-0.63 g vs. -0.22 g; $P<0.009)$ (Figure 2A).

Table 2 The effect of fish oil and saturated fat on body and tissue weights ${ }^{1}$

\begin{tabular}{lccc}
\hline & Fish oil diet & Saturated fat diet & P-value \\
\cline { 2 - 4 } End point body weight, ${ }^{2} g$ & $26.8 \pm 0.37$ & $28.2 \pm 0.64$ & 0.19 \\
Net weight gain, $^{3} g$ & $13.3 \pm 0.47$ & $15.6 \pm 0.53^{4}$ & 0.005 \\
Tissue weight & & & \\
$\quad$ Epididymal fat, g & $0.45 \pm 0.02$ & $0.61 \pm 0.74^{4}$ & 0.005 \\
$\quad$ Colon, g & $0.15 \pm<0.01$ & $0.12 \pm 0.01^{4}$ & $<0.013$ \\
Cecum, g & $0.19 \pm 0.01$ & $0.23 \pm 0.02$ & 0.26 \\
Liver, g & $1.01 \pm 0.03$ & $0.99 \pm 0.05$ & 0.1 \\
\hline
\end{tabular}

${ }^{1}$ Data are presented as mean \pm SE

${ }^{2}$ Measured after 60 day feeding period

${ }^{3}$ Difference between 60 day feeding period weights and pre-study values

${ }^{4}$ Significantly different form saturated fat diet

${ }^{5}$ Weights, after 2 hours post 500 ng LPS-challenge 


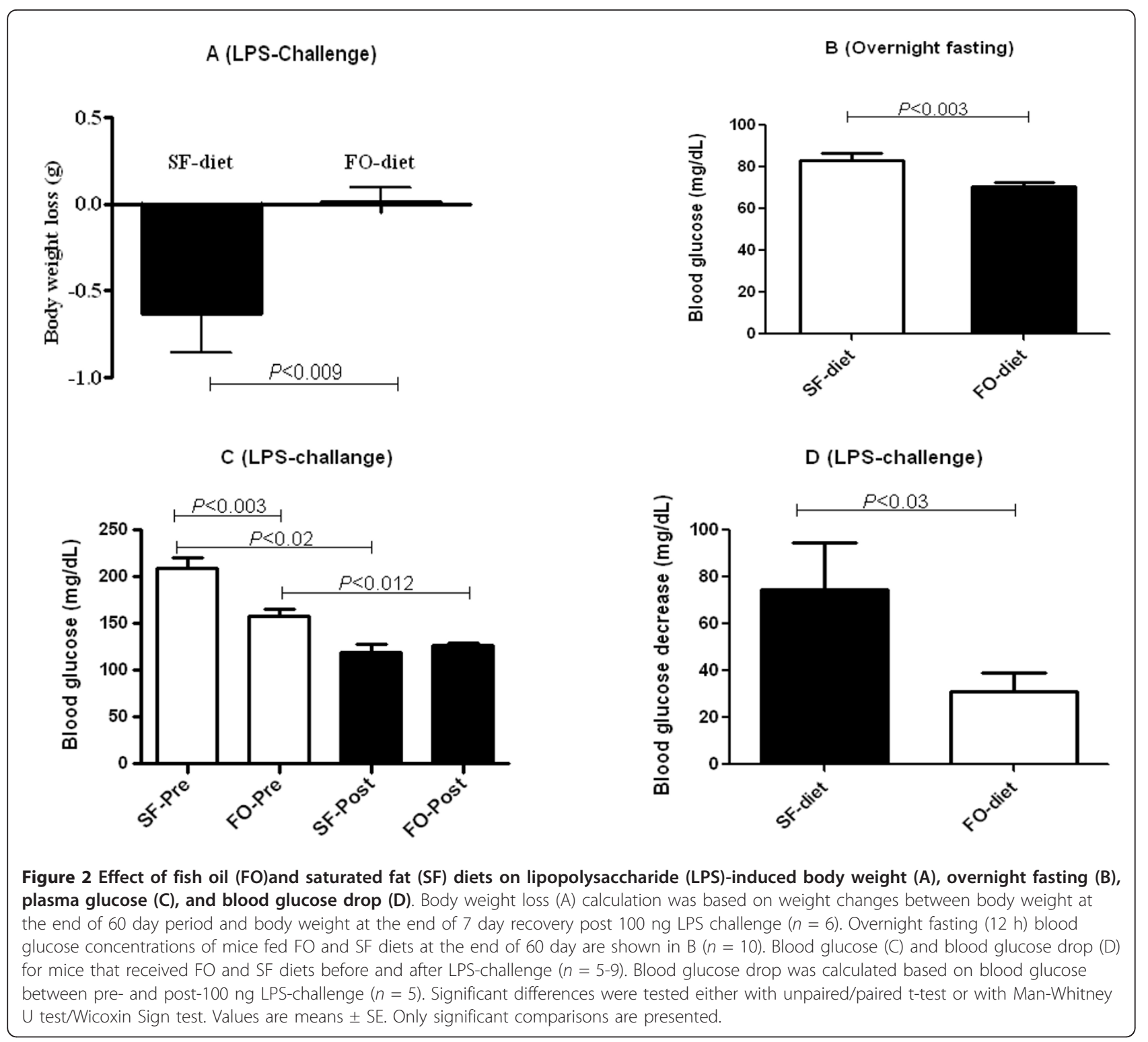

Effect of FO and SF diets, after LPS-challenge on glucose, insulin, and HOMA-IR

To investigate the effect of TLR-4 signaling on glucose metabolism, we injected LPS, the classic TLR-4 agonist, intraperitonially at a low dose of $100 \mathrm{ng} / \mathrm{mouse}$. To investigate the impact of FO diet in comparison with SF diet on glucose metabolism, we tested blood glucose concentrations after a 12-hour overnight fast at the end of 60 day feeding. FO diet group had significantly lower overnight fasting blood glucose concentrations compared to SF diet group $(70.8 \mathrm{mg} / \mathrm{dL}$ vs $83.3 \mathrm{mg} / \mathrm{dL})(P<$ 0.014 ) (Figure $2 \mathrm{~B}$ ). Both groups of mice showed a significant drop in blood glucose concentrations after LPSchallenge. However, no significant difference was observed in blood glucose between FO- and SF-fed mice after LPS- challenge (Figure 2C). A greater decrease in blood glucose concentration was observed with SF diet compared to FO diet after $100 \mathrm{ng}$ of LPS challenge (89.2 mg/dL vs $30.9 \mathrm{mg} / \mathrm{dL} ; P<0.03$ ) (Figure 2D).

After administration of $100 \mathrm{ng}$ of LPS, SF-fed mice had a higher mean insulin concentration compared to FO-fed mice (2.11 vs. $0.88 \mathrm{ng} / \mathrm{mL}$ ) (Figure 3A). However, these values were not significant $(P<0.06)$. We calculated HOMA-IR scores from fasting blood glucose and insulin concentrations to assess whether FO diet protected mice from IR. In fact, mice that received FO diet had significantly lower HOMA-IR scores compared to mice that received SF diet after 60-day feeding (5.0 vs. 13.6; $P<0.019)$ and after LPS-challenge (4.43 vs. 14.23; $P<0.04$ ) (Figure $3 \mathrm{~B}$ ). 


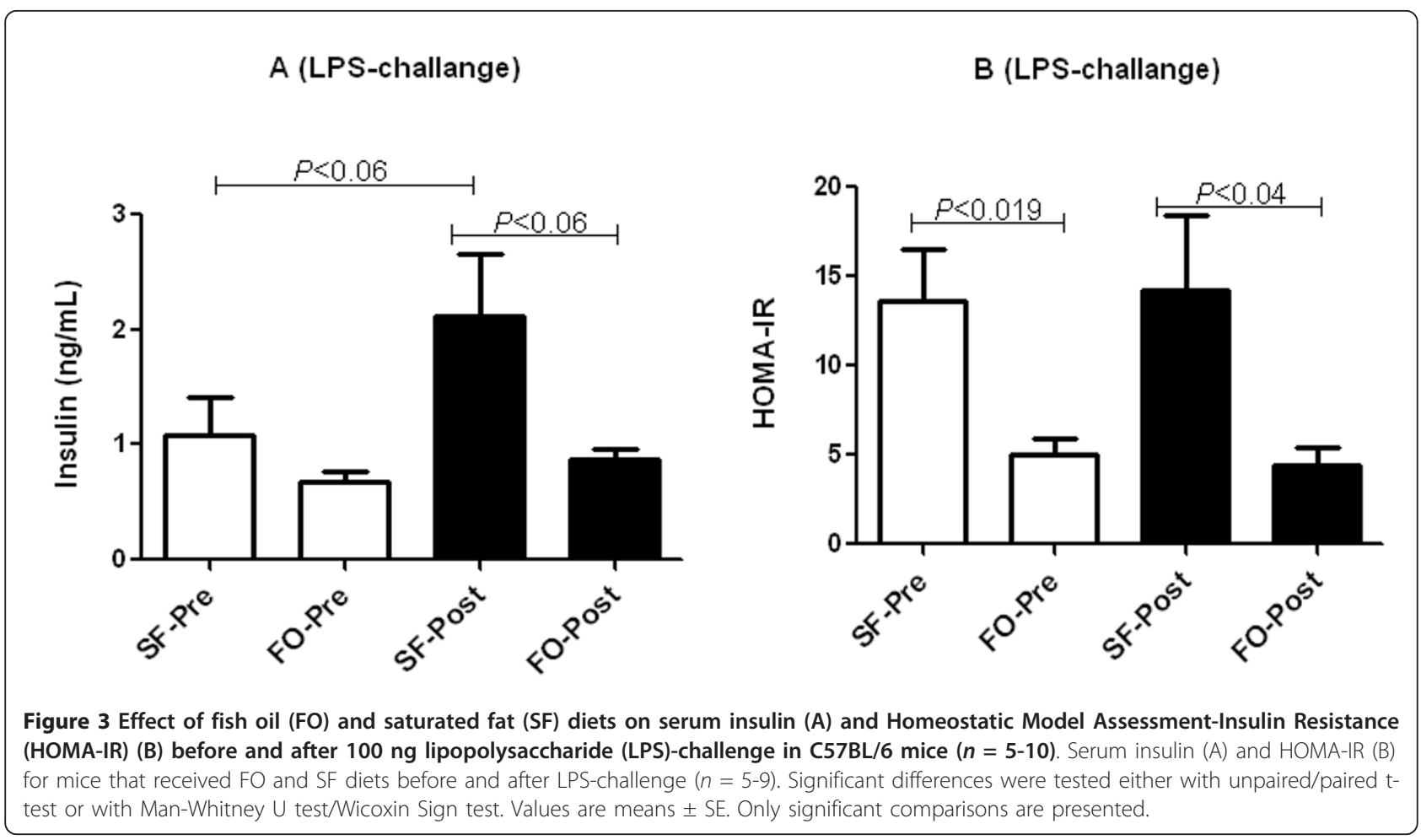

Effect of FO and SF diets, after LPS-challenge on serum cholesterol, leptin, and cytokines

After 60 days of feeding, FO diet group had significantly lower serum cholesterol concentrations when compared to SF diet group (97.6 mg/dL vs $183 \mathrm{mg} / \mathrm{dL})(P<0.01)$. As expected, SF diet was hypercholesterolemic compared to FO diet after 60 days of feeding $(P<0.001)$. These differences persisted between SF and FO diets even after LPS challenge. LPS administration had no impact on serum cholesterol (Figure 4A). There was no difference in mean serum leptin between the FO and SF diet groups at baseline or after LPS-challenge (Figure 4B).

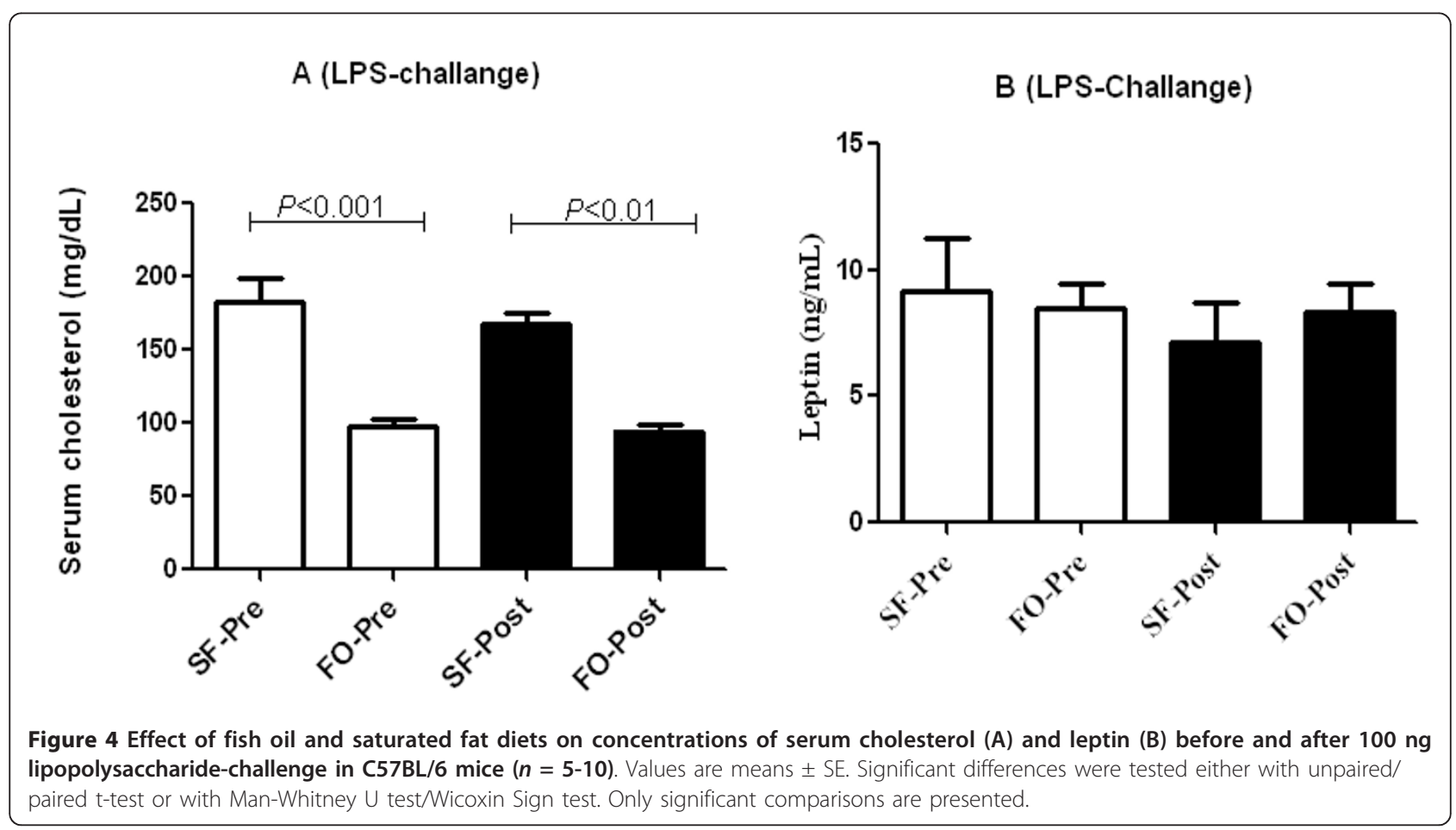


Mice that received SF diet had significantly higher mean serum IL- $1 \beta$ concentrations compared to those that received FO diet after 100 ng LPS-challenge (30.0 $\mathrm{pg} / \mathrm{mL}$ vs. $2.0 \mathrm{pg} / \mathrm{mL})(P=0.0004)$ (Figure $5 \mathrm{~A})$. As expected, with LPS-challenge, both in FO- and SF-fed mice had significantly higher concentrations of inflammatory markers such as serum TNF- $\alpha$ and KC. However, mean serum concentrations of KC (Figure 5B), TNF- $\alpha$ (Figure 5C), and IL-6 (data not shown) were not significantly different between mice that received FO and SF diets either at pre-LPS-challenge or post- LPS challenge.

\section{Discussion}

To our knowledge, this is the first study that reported the protective effect of a diet rich in FO in relation to a diet rich in SF against LPS-induced pathologies in mice with functional TLR-4. SF-fed mice that were challenged with LPS got sicker and had higher mortality rate compared to FO-fed mice. After LPS challenge, SF-fed mice lost more weight and had greater drop in blood glucose concentrations compared to FO-fed mice. These coincided with higher serum IL-1 $\beta$ concentrations in SF-fed mice challenged with LPS compared to their counterparts. Additionally, net body weight gain, abdominal fat weight, serum cholesterol, and blood glucose were significantly higher in SF-fed mice compared to FO-fed mice.

Although the food intake during the 60 day feeding was not significantly different between FO- and SF-fed mice, the net body weight gain and epididymal fat weight were significantly increased in SF-fed mice suggesting that the weight gain observed in SF-fed mice was due to type of fat administered and not due to

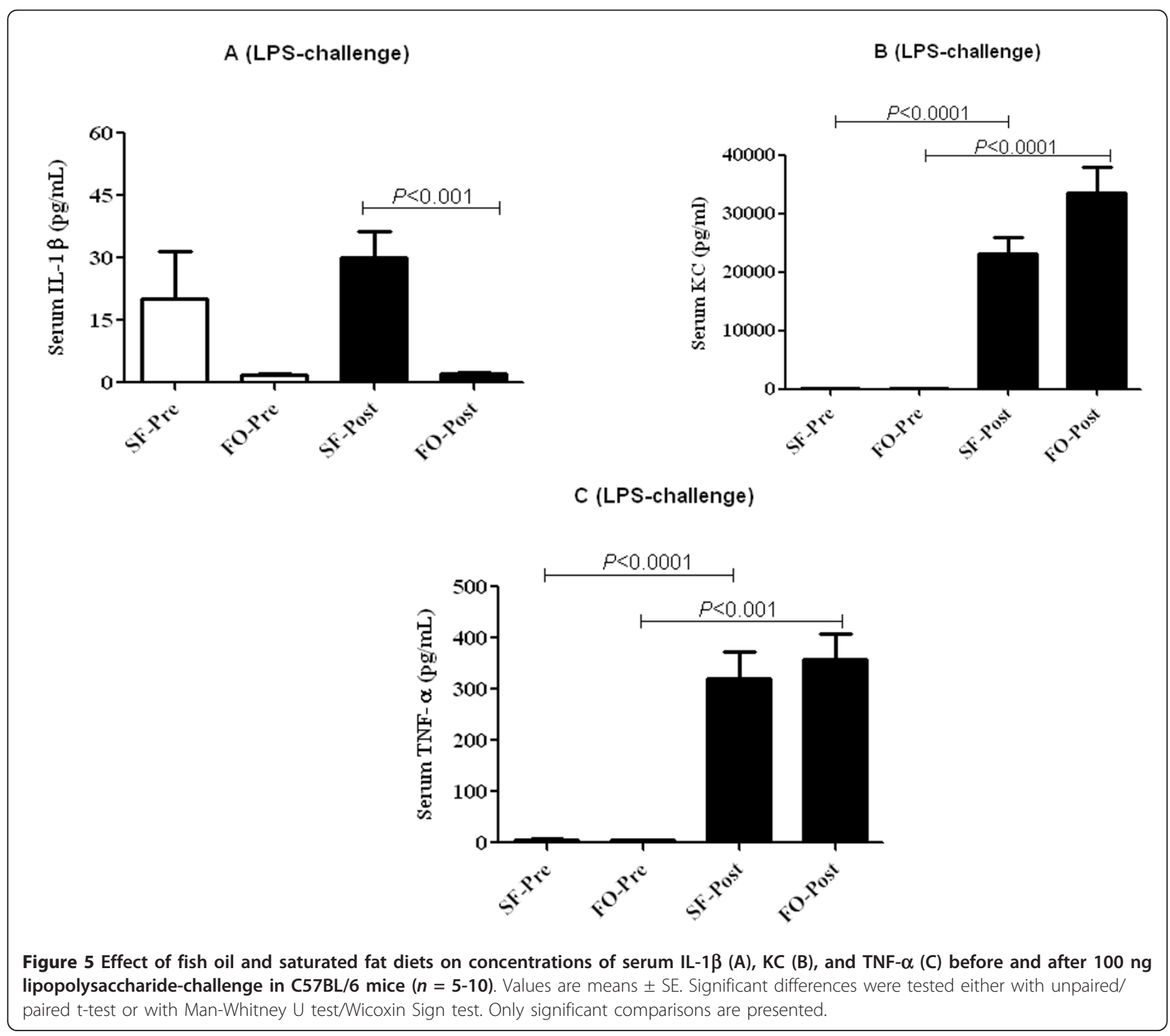


hyperphagia. Generally, increased adiposity is a cause for elevated inflammation and further fat intake/infusion is likely to lead elevated free fatty acids which further leads to elevated inflammation [24-26]. Intake of n-3 fatty acids from marine sources reduces adiposity by inhibiting the sterol regulatory element binding protein1 and thereby decreasing the expression of lipogenic genes (acetyl CoA carboxylase and fatty acid synthase), increasing the gene expression of lipolytic genes (hormone sensitive lipase and serum amyloid A) [27], and decreasing expression of perilipin, a lipid droplet-protective protein [28]. Similar to our findings, Samane et al [29] found that FO decreased visceral adiposity compared to a diet rich in lard. They also reported no difference in weight gain between mice fed a high fat diet with $6 \%$ of fat replaced by fish oil or argan oil (mainly oleic acid) for 4 weeks, suggesting the effect of fish oil on body weight is affected by the duration and amount of fish oil intake.

Another beneficial effect of FO diet in relation to SF diet is decreased circulating cholesterol. After 60-day feeding, on average, mice fed FO diet had $87.5 \%$ lower serum cholesterol compared to mice fed SF diet. Depressed circulating cholesterol is a well established cardioprotective factor [30]. Generally, decreased blood cholesterol is due to lowered LDL cholesterol. It has been well documented diets rich in FO are cardioprotective [31,32]. However, effects of FO on blood lipids have not been uniform [30]. Chang et al [32] reported that the cardioprotective effect of FO in comparison to SF diet was not related to blood cholesterol. In their study, SF and FO diets had similar increase in blood cholesterol but free fatty acids and triglycerdes were lower with FO diet in relation to SF diet. Increased blood cholesterol was likely due to higher cholesterol content of SF and FO diets [32]. Additionally, cardioprotective effect of n-3 fatty acids compared to SF was due to reduced total LDL uptake and cholesterol ester deposition in arterial walls [32,33].

Studies have shown that diets high in fat (other than FO) and specifically high in SF induced metabolic endotoxemia and adipose tissue inflammation by altering gut microbiota and permeability to LPS [34-36] and by stimulating TLR-4 expression [37]. Antibiotic treatment reversed these effects significantly [34]. Thus metabolic endotoxemia (increased circulating LPS) may partly explain the increased inflammation with SF diet. In our study, the SF diet group had a significant decrease in colon weight compared to FO diet group $(\mathrm{P}<0.013)$. This decrease in colon weight observed in the SF group may be a result of atrophy due to a change in the intestinal microbiota or increased colon weight in FO diet group due to protective effect of FO on the gut. More research investigating the effect of saturated fat and n-3 fatty acids on intestinal microbiota and pathobiology of gut is needed to verify this observation.

After administration of LPS, mice were observed for changes in behavior. In the post-500 ng LPS phase, 3 mice died in the SF group out of 9 (33.3\% mortality rate) and 1 mouse died out of 10 (10\% mortality rate) in the FO group suggesting that FO offered protection against LPS-induced sickness and mortality. Furthermore, after LPS-challenge, SF-fed mice had lost more body weight and experienced a greater decline in blood glucose (decrease was $42.8 \%$ with SF and $19.7 \%$ with FO) than FO-fed mice suggesting that the SF-fed mice were in a more catabolic state. Following the 60 day period, we noticed no overt in-between group differences in the physical appearance of mice. However, following $100 \mathrm{ng}$ LPS-challenge, the SF diet group mice became reclusive and shortly fell asleep. In contrast, the FO-fed mice exhibited no abnormal behavior. After the $500 \mathrm{ng}$ LPS-challenge, both groups of mice were moribund. However, mice in FO diet group recovered quicker (within 30 minutes) than the mice in SF diet group. These observations illustrate an overall protective effect of fish oil from LPS-induced ill health.

After 60 days of feeding, FO diet group had a 17.7\% decrease in fasting blood glucose compared to SF diet group $(P<0.01)$ suggesting overall protection of FO from hyperglycemia. Flachs $\mathrm{P}$ et al [38] reported a $\approx 4 \%$ decrease in blood glucose in mice fed a FO diet. Rossmeisl et al [39] reported a blood glucose decrease of $\approx 19.2 \%$ in mice fed DHA diet compared to mice fed a corn oil diet for 4 months. In contrast, Samane et al [29] reported no significant decrease in fasting blood glucose. It is likely that the differences in results in between these studies may be due to differences in duration of feeding and amount of FO present in experimental diets.

Although insulin concentration did not reach statistical significance, there was higher insulin concentration in SF group compared to FO group after mice were challenged with LPS $(P<0.06)$. FO diet group compared to SF diet group had lower HOMA-IR values after 60 day feeding and after LPS challenge. The observation of improved insulin sensitivity in rodents fed FO diet compared to rodents fed SF diet has been previously reported [39]. Differential effects of saturated and n-3 fatty acids on TLR-4 signaling may explain the variation in insulin resistance. Saturated fatty acids and LPS induce dimerization and recruitment of TLR-4 to the membrane which are essential for TLR-4 signaling. In contrast, DHA of FO inhibits the dimerization and recruitment of TLR-4 into the membrane [40] leading to attenuated TLR-4 signaling. In vivo studies have reported that FO is incorporated into the plasma membrane where it inhibits downstream 
signaling of TLR-4 [41,42] leading to decreased insulin resistance [43-45].

Obesity and DM2 are characterized by elevated circulating concentrations of inflammatory markers [46]. These inflammatory markers originate from adipose tissue [47]. In diet-induced obesity, macrophages infiltrate into white adipose tissue and these infiltrated macrophages produce inflammatory markers such as IL-1 $\beta[48,49]$. We found a protective effect of FO against IL-1 $\beta$, a potent inflammatory marker, in LPSchallenged mice. Several studies have demonstrated that consumption of FO decreased production of IL- $1 \beta$ from mononuclear cells [50-52]. Eevated IL-1 $\beta$ promotes insulin resistance [53]. IL-1 $\beta$ is produced from large pro-inflammatory protein complexes called inflammasomes [54]. These are part of innate immune system activated by various microbial stimuli. Other mechanisms through which FO exerts anti-inflammatory properties include displacement of arachidonic acid in the plasma membrane leading to the synthesis of anti-inflammatory PGE3 and LTB5 instead of PGE2 and LTB4, respectively [55]. Recent studies revealed that $\mathrm{n}-3$ fatty acids produce $\mathrm{E}$ - and D-series resolvins [56-58] which are found to be potently anti-inflammatory [59].

There is a possibility that the overall beneficial effect of FO against LPS-induced ill health that we found in our study may also be due to mechanisms unrelated to TLR-4 and NRLs. Although n-3 fatty acids from FO are known to antagonize the effects of LPS-induced TLR-4 signaling, the protection of FO diet could potentially be due to increased production of anti-inflammatory components of n-3 fatty acid-derived eicosanoids. Based on the findings from this study, consumption of a diet rich in $\mathrm{n}-3$ fatty acids from marine sources is beneficial against the deleterious effects of Gram negative bacterial infection.

\section{Acknowledgements}

This study was supported by the Research Initiative Grant Program, Georgia State University, Atlanta, GA. Part of this study was presented at the Experimental Biology Annual Meeting, April 2010, Anaheim, CA.

\section{Author details}

${ }^{1}$ Pathology and Laboratory Medicine, Department of Medicine, Emory University School of Medicine, Atlanta, GA 30322, USA. Division of Nutrition, School of Health Professions, College of Health and Human Sciences, Georgia State University, Atlanta, GA 30302, USA. ${ }^{3}$ Division of Endocrinology, Metabolism and Lipids, Department of Medicine, Emory University School of Medicine, Atlanta, GA 30322, USA.

\section{Authors' contributions}

MVK, TRZ, and VG designed research and conducted research; MVK, SMV, NP, and JDA conducted animal study, collected data, and analyzed data; VG was the principal investigator and obtained funding for the research, supervised the study, wrote the manuscript, and revised the manuscript. All authors read and approved the final manuscript.

\section{Competing interests}

M. Vijay-Kumar, S. Vanegas, N. Patel, J. D. Aitken, T. R. Ziegler, and V. Ganji have no conflict of interest.

Received: 20 December 2010 Accepted: 9 March 2011

Published: 9 March 2011

\section{References}

1. Calder PC: $n-3$ polyunsaturated fatty acids, inflammation, and inflammatory diseases. Am J Clin Nutr 2006, 83:1505S-1519S.

2. Wellen KE, Hotamisligil GS: Inflammation, stress, and diabetes. J Clin Invest 2005, 115:1111-9.

3. Oh K, Hu FB, Manson JE, Stampfer MJ, Willett WC: Dietary fat intake and risk of coronary heart disease in women: 20 years of follow-up of the nurses' health study. Am J Epidemiol 2005, 161:672-9.

4. Antuna-Puente B, Feve B, Fellahi S, Bastard JP: Adipokines: the missing link between insulin resistance and obesity. Diabetes Metab 2008, 34:2-11.

5. Elks CM, Francis J: Central adiposity, systemic inflammation, and the metabolic syndrome. Curr Hypertens Rep 2010, 12:99-104.

6. Devaraj S, Dasu MR, Rockwood J, Winter W, Griffen SC, Jialal I: Increased toll-like receptor (TLR) 2 and TLR4 expression in monocytes from patients with type 1 diabetes: further evidence of a proinflammatory state. J Clin Endocrinol Metab 2008, 93:578-83.

7. Takeda K, Kaisho T, Akira S: Toll-like receptors. Annu Rev Immunol 2003, 21:335-76

8. Takeda K, Akira S: Toll-like receptors in innate immunity. Int Immunol 2005, 17:1-14.

9. Akira $S$, Uematsu $S$, Takeuchi O: Pathogen recognition and innate immunity. Cell 2006, 124:783-801.

10. Beutler B: Inferences, questions and possibilities in Toll-like receptor signaling. Nature 2004, 430:257-263.

11. Akira S: Toll-like receptors and innate immunity. Adv Immunol 2001, 78:1-56.

12. Poltorak $\mathrm{A}, \mathrm{He} X$, Smirnova I, et al: Defective LPS signaling in $\mathrm{C} 3 \mathrm{H} / \mathrm{HeJ}$ and C57BL/10ScCr mice: mutations in Tlr4 gene. Science 1998, 282:2085-8.

13. Faure E, Thomas L, Xu H, Medvedev A, Equils O, Arditi M: Bacterial lipopolysaccharide and IFN-gamma induce Toll-like receptor 2 and Tolllike receptor 4 expression in human endothelial cells: role of NF-kappa B activation. J Immunol 2001, 166:2018-24.

14. Song MJ, Kim KH, Yoon JM, Kim JB: Activation of Toll-like receptor 4 is associated with insulin resistance in adipocytes. Biochem Biophys Res Commun 2006, 346:739-45.

15. Wang Z, Nakayama T: Inflammation, a link between obesity and cardiovascular disease. Mediators Inflamm 2010, 2010:535918.

16. Wisse BE: The inflammatory syndrome: the role of adipose tissue cytokines in metabolic disorders linked to obesity. J Am Soc Nephrol 2004, 15:2792-800

17. Neels JG, Olefsky JM: Inflamed fat: what starts the fire? J Clin Invest 2006, 116:33-5.

18. Sacks FM, Katan M: Randomized clinical trials on the effects of dietary fat and carbohydrate on plasma lipoproteins and cardiovascular disease. Am J Med 2002, 113(Suppl 9B):13S-24S.

19. Harris WS, Connor WE, Alam N, Illingworth DR: Reduction of postprandial triglyceridemia in humans by dietary n-3 fatty acids. J Lipid Res 1988, 29:1451-60.

20. Lee JY, Sohn KH, Rhee SH, Hwang D: Saturated fatty acids, but not unsaturated fatty acids, induce the expression of cyclooxygenase- 2 mediated through Toll-like receptor 4. J Biol Chem 2001, 276:16683-9.

21. Lee JY, Plakidas A, Lee WH, et al: Differential modulation of Toll-like receptors by fatty acids: preferential inhibition by $n-3$ polyunsaturated fatty acids. J Lipid Res 2003, 44:479-86.

22. Tsukumo DM, Carvalho-Filho MA, Carvalheira JB, et al: Loss-of-function mutation in Toll-like receptor 4 prevents diet-induced obesity and insulin resistance. Diabetes 2007, 56:1986-98.

23. Davis JE, Gabler NK, Walker-Daniels J, Spurlock ME: Tlr-4 deficiency selectively protects against obesity induced by diets high in saturated fat. Obesity (Silver Spring) 2008, 16:1248-55

24. Ghanim H, Aljada A, Hofmeyer D, et al: Circulating mononuclear cells in the obese are in a proinflammatory state. Circulation 2004, 110:1564-71.

25. Patel P, Ghanim H, Ravishankar S, et al: Prolonged reactive oxygen species generation and nuclear Factor-KB activation after a high-fat 
high-carbohydrate meal in the obese. J Clin Endocrinol Metab 2007, 92:4476-79.

26. Tripathy $D$, Mohanty $P$, Dhindsa $S$, et al: Elevation of free fatty acids induces inflammation and impairs vascular reactivity in healthy subjects. Diabetes 2003, 52:2882-7.

27. Tai CC, Ding ST: $\mathrm{N}-3$ polyunsaturated fatty acids regulate lipid metabolism through several inflammation mediators: mechanisms and implications for obesity prevention. J Nutr Biochem 2010, 21:357-63.

28. Wang YC, Kuo WH, Chen $C Y$, et al: Docosahexaenoic acid regulates serum amyloid A protein to promote lipolysis through down regulation of perilipin. J Nutr Biochem 2010, 21:317-24.

29. Samane $S$, Christon R, Dombrowski $L$, et al: Fish oil and argan oil intake differently modulate insulin resistance and glucose intolerance in a rat model of dietary-induced obesity. Metabolism 2009, 58:909-19.

30. Balk EM, Lichtenstein AH, Chunga M, Kupelnick B, Chewa P, Laua J: Effects of omega-3 fatty acids on serum markers of cardiovascular disease risk: A systematic review. Atherosclerosis 2006, 189:19-30.

31. Wang C, Harris WS, Chung M, et al: n-3 Fatty acids from fish or fish-oil supplements, but not a-linolenic acid, benefit cardiovascular disease outcomes in primary- and secondary-prevention studies: a systematic review. Am J Clin Nutr 2006, 84:5-17.

32. Chang $C L$, Seo T, Matsuzaki $M$, et al: $n-3$ fatty acids reduce arterial LDLcholesterol delivery and arterial lipoprotein lipase levels and lipase distribution. Arterioscler Thromb Vasc Biol 2009, 29:555-61.

33. Seo T, Qi K, Chang C, et al: Saturated fat-rich diet enhances selective uptake of LDL cholesteryl esters in the arterial wall. J Clin Invest 2005, 115:2214-22.

34. Cani PD, Bibiloni R, Knauf $C$, et al: Changes in gut microbiota control metabolic endotoxemia-induced inflammation in high-fat diet-induced obesity and diabetes in mice. Diabetes 2008, 57:1470-81.

35. de La Serre CB, Ellis CL, Lee J, Hartman AL, Rutledge JC, Raybould HE: Propensity to high-fat diet-induced obesity in rats is associated with changes in the gut microbiota and gut inflammation. Am J Physiol Gastrointest Liver Physiol 2010, 299:G440-8.

36. Drewe J, Beglinger C, Fricker G: Effect of ischemia on intestinal permeability of lipopolysaccharides. Eur J Clin Invest 2001, 31:138-44.

37. Deopurkar R, Ghanim H, Friedman J, et al: Differential effects of cream, glucose, and orange juice on inflammation, endotoxin, and the expression of Toll-like receptor-4 and suppressor of cytokine signaling-3. Diabetes Care 2010, 33:991-7.

38. Flachs P, Mohamed-Ali V, Horakova O, et al: Polyunsaturated fatty acids of marine origin induce adiponectin in mice fed a high-fat diet. Diabetologia 2006, 49:394-7.

39. Rossmeisl M, Jelenik T, Jilkova Z, et al: Prevention and reversal of obesity and glucose intolerance in mice by DHA derivatives. Obesity 2009, 17:1023-31.

40. Wong SW, Kwon MJ, Choi AM, Kim HP, Nakahira K, Hwang DH: Fatty acids modulate Toll-like receptor 4 activation through regulation of receptor dimerization and recruitment into lipid rafts in a reactive oxygen species-dependent manner. J Biol Chem 2009, 284:27384-92.

41. Weatherill AR, Lee JY, Zhao L, Lemay DG, Youn HS, Hwang DH: Saturated and polyunsaturated fatty acids reciprocally modulate dendritic cell functions mediated through TLR4. J Immunol 2005, 174:5390-7.

42. Ajuwon KM, Spurlock ME: Palmitate activates the NF-kappaB transcription factor and induces IL-6 and TNFalpha expression in 3T3-L1 adipocytes. J Nutr 2005, 135:1841-6.

43. Hirosumi J, Tuncman G, Chang L, et al: A central role for JNK in obesity and insulin resistance. Nature 2002, 420:333-6.

44. Kim JA, Yeh DC, Ver M, et al: Phosphorylation of Ser24 in the pleckstrin homology domain of insulin receptor substrate- 1 by Mouse Pelle-like kinase/interleukin-1 receptor-associated kinase: cross-talk between inflammatory signaling and insulin signaling that may contribute to insulin resistance. J Biol Chem 2005, 280:23173-83.

45. Gao Z, Hwang D, Bataille F, Lefevre M, York D, Quon MJ, Ye J: Serine phosphorylation of insulin receptor substrate 1 by inhibitor kappa B kinase complex. J Biol Chem 2002, 277:48115-21.

46. Trayhurn P, Wood IS: Signalling role of adipose tissue: adipokines and inflammation in obesity. Biochem Soc Trans 2005, 33:1078-81.

47. Berg AH, Scherer PE: Adipose tissue, inflammation, and cardiovascular disease. Circ Res 2005, 96:939-49.
48. Xu H, Barnes GT, Yang $Q$, et al: Chronic inflammation in fat plays a crucial role in the development of obesity-related insulin resistance. J Clin Invest 2003, 112:1821-30

49. Weisberg SP, McCann D, Desai M, Rosenbaum M, Leibel RL, Ferrante AW Jr: Obesity is associated with macrophage accumulation in adipose tissue. J Clin Invest 2003, 112:1796-808.

50. Endres $\mathrm{S}$, Ghorbani R, Kelley VE, et al: The effect of dietary supplementation with $n-3$ polyunsaturated fatty acids on the synthesis of interleukin-1 and tumor necrosis factor by mononuclear cells. N Engl J Med 1989, 320:265-71.

51. Meydani SN, Endres S, Woods MM, et al: Oral (n-3) fatty acid supplementation suppresses cytokine production and lymphocyte proliferation: comparison between young and older women. J Nutr 1991, 121:547-55.

52. Caughey GE, Mantzioris E, Gibson RA, Cleland LG, James MJ: The effect on human tumor necrosis factor alpha and interleukin 1 beta production of diets enriched in $n-3$ fatty acids from vegetable oil or fish oil. Am J Clin Nutr 1996, 63:116-22

53. Lagathu C, Yvan-Charvet L, Bastard JP, Maachi M, Quignard-Boulangé A, Capeau J, Caron M: Long-term treatment with interleukin-1beta induces insulin resistance in murine and human adipocytes. Diabetologia 2006, 49:2162-73.

54. Naik E, Dixit VM: Modulation of inflammasome activity for the treatment of auto-inflammatory disorders. J Clin Immunol 2010, 30:485-90.

55. Bagga D, Wang I, Farias-Eisner R, Glaspy JA, Reddy ST: Differential effects of prostaglandin derived from omega- 6 and omega-3 polyunsaturated fatty acids on COX-2 expression and IL-6 secretion. Proc Natl Acad Sci USA 2003, 100:1751-6.

56. Serhan CN, Clish CB, Brannon J, Colgan SP, Chiang N, Gronert K: Novel functional sets of lipid-derived mediators with antiinflammatory actions generated from omega-3 fatty acids via cyclooxygenase 2-nonsteroidal antiinflammatory drugs and transcellular processing. J Exp Med 2000, 192:1197-204.

57. Serhan CN, Hong S, Gronert K, et al: Resolvins: a family of bioactive products of omega-3 fatty acid transformation circuits initiated by aspirin treatment that counter proinflammation signals. J Exp Med 2002, 196:1025-37.

58. Hong S, Gronert K, Devchand PR, Moussignac RL, Serhan CN: Novel docosatrienes and 17S-resolvins generated from docosahexaenoic acid in murine brain, human blood, and glial cells. Autacoids in antiinflammation. J Biol Chem 2003, 278:14677-87.

59. Seki H, Tani Y, Arita M: Omega-3 PUFA derived anti-inflammatory lipid mediator resolvin E1. Prostaglandins Other Lipid Mediat 2009, 89:126-30.

doi:10.1186/1743-7075-8-16

Cite this article as: Vijay-Kumar et al:. Fish oil rich diet in comparison to saturated fat rich diet offered protection against lipopolysaccharideinduced inflammation and insulin resistance in mice. Nutrition \& Metabolism 2011 8:16.

\section{Submit your next manuscript to BioMed Central and take full advantage of:}

- Convenient online submission

- Thorough peer review

- No space constraints or color figure charges

- Immediate publication on acceptance

- Inclusion in PubMed, CAS, Scopus and Google Scholar

- Research which is freely available for redistribution

Submit your manuscript at www.biomedcentral.com/submit
C Biomed Central 